\title{
ENSAIOS
}

\section{A TECNOLOGIA de GESTÃO E O HOLOCAUSTO: É POSSÍVEL "HACKEAR" ISSO?}

\section{RESUMO}

Neste ensaio, discutimos a condição, vista por Bauman pelas lentes do Holocausto, do que ainda se apresenta como lógica dominante das tecnologias de gestão disseminadas na formação em Administração no Brasil. Mostra-se que, além das graduações enviesadas por uma racionalidade questionável, há um imaginário que condiciona a percepção geral e afeta as possibilidades emancipatórias dos estudantes. Contextualiza-se, assim, o que o Holocausto pode representar em termos da tecnologia de gestão; aborda-se uma orientação epistemológica a ser assimilada como ponto de partida nos desenvolvimentos em torno de racionalidades alternativas e, com um exemplo de protagonismo de estudantes de Administração na Internet, situa-se uma distinção entre mídia social e mídia tática, de modo a falar sobre possíveis hackings nesse campo. Conclui-se enfatizando a possibilidade do estudo/atuação das/com tecnologias online a partir da distinção entre modelo de negócio e prática política.

Palavras-chave: Formação de administradores. Tecnologia de gestão. Management. Hacking.

\section{A TÍTULO DE INTRODUÇÃO}

A motivação para o que se discute neste ensaio se inicia com o questionamento de Reed sobre como "ignorar aquilo que Bauman chama de 'padrões de ação tecnológico-burocráticos modernos e a mentalidade que esses institucionalizam, geram, sustentam e reproduzem', e que consistiram nos alicerces psicossociais e nas precondições para o Holocausto.” (REED, 1998, p. 62). Isso chama a atenção para o que ainda está posto nos processos de gestão contemporâneos: a racionalidade moderna, burocrática, dominante e totalizadora, que providencia as condições para uma

Orlando Gomes da Silva o2@riseup.net Doutorando em Administração pela Universidade Federal de Pernambuco (UFPE). Professor da Universidade Federal de Campina Grande, UFCG Sousa - PB - BR. solução técnica (BAUMAN, 1998), o extermínio em massa de milhões de seres humanos.

Nesse cenário, a formação de administradores no Brasil, particularmente aquela direcionada para práticas empresariais da iniciativa privada, parece permanecer distante da problemática. Por isso, o foco do ensaio é na problematização da forma como se lida com tecnologias de gestão nas graduações em administração 
e na noção que há de epistemologias e práticas, as quais permitem outros olhares, já que as tecnologias podem ser projetadas, utilizadas e ensinadas com outros objetivos diferentes dos idealizados em seu design.

Hackings, ou seja, práticas em torno de tecnologias por pessoas interessadas "com habilidades técnicas e disposição curiosa para a busca do livre conhecimento" (PARRA, 2012, p. 113) são possiblidades de ação política. To hack é uma atitude cultural que está na base dos relacionamentos contemporâneos com as tecnologias (CASTELLS, 2003) e que pode inspirar diferentes ações de constituição de poder com informação (WARK, 2004).

Pensa-se nas tecnologias como modos de revelar (HEIDEGGER, 2007; SILVA, 2007), vendo-as, de certa forma, como construções (BIJKER, 2009; PINCH; BIJKER, 1987), e mais especificamente, como agrupamentos provisórios entre diferentes atuações do que é dito social e o que é dito técnico, sem identidades previamente delimitadas (CALLON, 1984; LATOUR, 2000, 2001), uma vez que o que vem a ser tecnologia está em constante negociação e contestação nas formas que é produzida, disseminada e utilizada (ESCOBAR et al., 1994; HINE, 2000).

Dessa maneira, formulam-se, a seguir, algumas considerações sobre conhecimento e formação em administração no Brasil, para, logo em seguida, caracterizar-se uma relação entre a tecnologia de gestão moderna e o Holocausto. Por fim, aponta-se para uma alternativa epistemológica aos processos tecnológicos de gestão, e contextualizam-se, como um exemplo prático, as possibilidades de ação online com mídia tática, hacking, para atuação nessa realidade.

\section{O MANAGEMENT E A FORMAÇÃO EM ADMINISTRAÇÃO}

No estabelecimento inicial dos estudos sobre organizações - final século XIX - a promessa era de garantia de progresso material e social "por meio do incremento tecnológico contínuo, da organização moderna e da ad- ministração científica." (REED, 1998, p. 62). Porém, em pleno século XXI, ainda se veem graves problemas que permitem questionar a visão epistemológica dominante que prega a efetividade técnica das organizações e caminha lado a lado com o viés ideológico da teoria administrativa.

É o composto técnico, ideológico e prático industrial que estabelece a administração moderna (SHENHAV, 2003), a administração

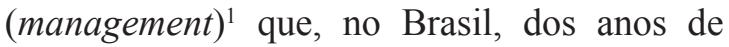
1970 já é apontada como um conhecimento ideologicamente estruturado em associação ao capitalismo de então (TRAGTEMBERG, 2006) e todo um aparato cultural da civilização industrial. Logo, a crítica não é nova. Porém, a crítica daquele momento não foi assimilada pelos conteúdos das graduações em administração no Brasil e, nas décadas seguintes, ingressou-se em um processo acelerado de adequação ao cenário global em que se moldam junto as narrativas dominantes sobre a administração.

Nesta visão, que encontra respaldo em outros autores (MASCARENHAS; ZAMBALDI; MORAES, 2011; NICOLINI, 2003; RIBEIRO; SACRAMENTO, 2010), as escolas de administração e os cursos de administração no Brasil são elementos importantes de um projeto global/Brasil associado à lógica do capitalismo industrial, devido à íntima relação entre o management e a racionalidade econômica dominante (AKTOUF, 2004). Trata-se da produção de um imaginário em torno de uma sociedade cientificamente organizada, que é fortemente planejada, defendida e colocada em andamento para se tornar realidade. Tal visão se ancora ainda na compreensão de que o desenvolvimento do capitalismo, em suas diferentes versões, esteja sempre atrelado ao discurso do management $\mathrm{e}$ ao que prescrevem as consultorias corporativas (BOLTANSKI; CHIAPELLO, 2009), o mesmo discurso do management amplamente praticado em nossas graduações.

Atualmente, o cenário epistemológico se mostra mais diverso (PAULA, 2016), porém a formação em administração é ainda vítima da divisão intelectual do trabalho nas universida- 
des brasileiras. Não é difícil ver, em nosso meio, que a pós-graduação (pesquisa por excelência) está pouco preocupada com a graduação. Pesquisador quer pesquisar; graduação significa lecionar (DEMO, 1991). Com a ênfase na pesquisa como função de status e propiciadora de mais recursos para o trabalho nas universidades, infelizmente, muitos esqueceram que são as graduações que formam o profissional da área. A pós-graduação pode aperfeiçoar ou não, pode conferir mais poder formal por causa dos títulos, mas quem forma o profissional para os mercados (sic!) é a graduação que continua atrelada a pressupostos e imaginários conformadores de uma situação nada satisfatória, visto que até a base do trabalho, o tipo de trabalho principal de geração de valor no capitalismo contemporâneo é outro, é imaterial, estando relacionado à manipulação de informação e de relacionamentos (HARDT; NEGRI, 2001).

A formatação teórica da graduação em administração ainda é essencialmente difusão de tecnologia de gestão enviesada pelas narrativas do management. $\mathrm{O}$ aparato imaginário dos estudantes de administração está muito associado à lógica figurativa do pop-management (WOOD JUNIOR; PAULA, 2002), que veio se estabelecendo da metade do século XX para cá e que é, em outra forma de se ver, parte das narrativas de base do capitalismo reestruturando-se, constituindo um novo espírito (BOLTANSKI; CHIAPELLO, 2009).

Mas essa outra forma de se ver se apresenta geralmente como assunto chato, deixado de lado para dar mais espaço para as ferramentas de gestão do management. Afinal, as fórmulas de consultoria são muito mais atraentes e se travestem de teoria "validada cientificamente" com muita facilidade (AKTOUF, 2004), enquanto a teoria social é bem mais complexa, não oferece "soluções" práticas de gestão e geralmente questiona o status quo das práticas de gestão ensinadas pelas escolas de administração.

Colabora ainda para a ampla assimilação do management o que chamamos de adestramento midiático (PEREIRA, 2007; ROCHA; COSTA, 2012), ou seja, todo o mecanismo de comunicação e publicidade contemporâneos já colocam os estudantes na sala de aula com expectativas totalmente enviesadas do que seja administração. Resumindo, quem vai para um curso de administração, por escolha, geralmente não está aberto para discutir teoria social, epistemologias etc. Quem vai para um curso de administração está imerso em um imaginário midiático sobre administração-managament que circula nos diferentes espaços das relações cotidianas e, infelizmente, também é alimentado por espaços de destaque do campo da formação em gestão, como os conselhos profissionais de administração (CFA, CRAs) e entidades como o SEBRAE. E ainda pior, por muitos professores universitários, ou seja, é difícil escapar do adestramento, ou, para usar um termo mais leve, da aculturação. Uma discussão como esta, da visão tecnológica do Holocausto, associada aos processos centrais do nosso aprendizado em administração, torna-se ainda mais difícil de ser assimilada.

\section{O HOLOCAUSTO E A TECNOLO- GIA DE GESTÃO}

"O Holocausto foi a perseguição e o extermínio sistemático, burocraticamente organizado e patrocinado pelo governo nazista, de aproximadamente seis milhões de judeus pela Alemanha e seus então colaboradores." (USHMM, 2016, online). Ocorrido durante a Segunda Guerra Mundial, quando os nazistas assumiram o poder na Alemanha, trazendo consigo a crença de serem raça superior e perseguindo judeus e outros grupos sociais, também por motivos políticos e ideológicos. "Entre 1941 e 1944, [...] [foram deportados] milhões de judeus da Alemanha, [...] [territórios ocupados e países aliados] [...], para guetos e centros de extermínio [...], onde eram mortos nas instalações de gás especialmente criadas para aquele fim." (USHMM, 2016, online).

Essa tragédia costuma ser vista como engendrada e conduzida de acordo com a tirania de certos dirigentes e os interesses de certos grupos sociais, porém, de forma assustadora e 
chocante, pode-se ver como possibilitada pelas próprias configurações tecnológicas de gestão estabelecidas pela modernidade burocrática (BAUMAN, 1998), ou seja, possibilitada por aquilo que se aprende a praticar em uma graduação de administração, desde o começo, na lógica subjacente às ordenações de departamentalização, autoridade, hierarquia, responsabilidade e outras que formam a tecnologia de gestão dominante.

Os desenvolvimentos da tecnologia de gestão nos anos da Segunda Guerra Mundial foram intensos, principalmente a partir do uso pelos militares de técnicas de programação e análise matemática para a identificação de pontos mais favoráveis de operação, sendo essas abordagens que deram origem à pesquisa operacional (CORRÊA, 2003). Além disso, nos anos imediatamente anteriores à guerra, uma profícua produção de conhecimento em torno de instrumentos de controle ideológico e psicológico vem, com a chamada escola das relações humanas, a atender às necessidades das burocracias em manter o poder hierárquico, apresentando uma "adequada" abordagem psicológica subordinada ao econômico (MOTTA, 2001, p. 78) ou, mais preciso seria dizer, ao crematístico $^{2}$ (AKTOUF, 2004).

O Holocausto pode ser visto como uma solução técnica racional, pois adotou, na relação, meios e fins para o humano como um recurso, um material à disposição (COOPER, 2002), em face das decisões a serem tomadas com a tecnologia de gestão disponível, a tecnologia da organização burocrática (FARIA; MENEGHETTI, 2011; MOTTA; BRESSER-PEREIRA, 2004). A razão inaugurada pela modernidade, que permeia a ciência ocidental, compatibiliza-se com a estrutura normativa da sociedade centrada no mercado (RAMOS, 1989), por isso se houver algo de não racional no assassinato em massa de Judeus, isso está associado como uma ausência muito mais à burocracia, pois a tecnologia não tem moral intrínseca.

A tecnologia, uma vez colocada em andamento, atua como um programa com decisões quase automáticas que vão desempenhan- do-se em função das associações com outros entes, pessoas, ideias, condições naturais, para fazeres específicos (LATOUR, 2000). No caso da tecnologia de gestão, o experimento de Milgram $^{3}$ é um excelente exemplo de como a burocracia, destacando seus aspectos de hierarquia e autoridade, pode ser compreendida também como possibilitadora de um caminho, ainda que moralmente questionável, racional.

Bauman (1998) se utiliza dos resultados do experimento de Milgram para corroborar sua explicação comportamental para o Holocausto, colocando em evidência obrigações situacionais e uma noção de tecnologia moralizada e responsabilidade flutuante, todas as condições que ainda estão aí presentes. A não aceitação da possibilidade racional burocrática, então, só acontece a partir de fora, ou como parece mais adequado dizer, só acontece caso seja problematizada sua inclusão por ausência nos mecanismos da tecnologia. A técnica por si só, os mecanismos por eles mesmos, de engendramento das funções tecnológicas, como a impessoalidade, as hierarquias formais, a delegação e o poder e todos os aparatos tecnoburocráticos das organizações, dos conhecimentos formais, que produzimos sobre organizações do final do século XIX para cá, constituem tentativas de tecnologias de controle das execuções de diferentes atividades (DINIZ, 2004), a custos, dadas outras racionalidades como imponderáveis (SANTOS, 2002), restritos apenas ao seu aparato interno de justificações não morais. E isso vem conformando o que se apresenta como administração até hoje.

Por isso, se for possível falar em algo como uma tese de Bauman (1998) do que impediria um segundo Holocausto, essa tese se apoiaria apenas em uma espécie de fé (sem conotação pejorativa nenhuma para esse termo) de que pode haver, na humanidade, algo que é independente da cultura, algo como uma natureza humana, que se apresenta também em seu aspecto moral, ou que as culturas contêm um padrão moral comum, portanto, parte do que lhes define como humanos, que pode ser confiado como um mecanismo de segurança a 
quase autonomia tecnológica.

As possibilidades de compreensão, fazeres e demais associações com a quase autonomia tecnológica, aceitando a fé de Bauman com relação à natureza humana ou considerando a possibilidade de qualquer outra coisa em seu lugar, mostram que o aparato e a relação entre os mecanismos burocráticos que se criaram para o extermínio de milhões de judeus, para a produção do Holocausto, como uma solução final, um conjunto de táticas últimas, foi e possui as condições de possibilidade de ainda ser, dadas as características tecnológicas das burocracias e fazendo-se em suas relações com a burocracia, a solução mais racional para o tipo de situação, a solução tecnológica da racionalidade burocrática, administrativa, moderna.

Para um leitor menos imerso nos estudos organizacionais, porém, talvez não esteja claro, porque se fala de burocracia e tecnologia de gestão intercambiavelmente. Isso porque as compreensões do que é o tecnológico também estão genericamente enviesadas por o que aqui já se chama de "adestramento midiático" e porque a discussão sobre tecnologias em sua maioria foca mais em certas dimensões aparentes do fenômeno técnico (TRIGUEIRO, 2008), objetos, equipamentos, elementos tidos popularmente como tecnologia. Contudo, a burocracia é um sistema de poder a partir de conhecimento aplicado, logo, tecnologia de gestão. Assim, vê-se como importante a noção de que há alternativas epistemológicas a uma racionalidade dominante, além de possibilidades, também tecnológicas, para atuação e intervenção nessas realidades, é disso que se trata a seguir.

\section{RACIONALIDADE TECNOLÓGI- CA DOMINANTE, INTERNET E HACKING}

Para se compreenderem as ausências na racionalidade tecnológica dominante e o que há de emergente ao nosso redor para lidar com essas faltas, pode-se aproximar do que Santos (2002) chama de um par de sociologias, das ausências e das emergências. Que, em resumo, vê que o tipo de razão, totalizante, da modernidade é um problema para a emergência de outras racionalidades. Dessa maneira, é preciso perceber que essa totalização é apenas o que é imposto, e, nessas imposições, o atendimento a diferentes demandas do fazer humano está ausente, por isso, ao nosso redor, emergem soluções precárias e provisórias para essas necessidades não atendidas. Na visão de Santos (2002), é necessário escrutinar as ausências e entender como potencializar, dar força de andamento, direcionar as emergências.

O estabelecimento das formas de conhecimento nos procedimentos profissionais dominantes é um processo relacional político, o que faz que um profissional escolha método $a$ ou $b$ de trabalho que está definido a partir das possibilidades de certa maneira colocadas pela tecnologia utilizada (MOL, 2002). Ao manter-se uma racionalidade como mecanismo essencial da tecnologia, da organização científica, da forma que essa parece ter alcançado seu apogeu de narrativa amplamente aceita no final do século XIX e continuado a se desenvolver durante o século XX e até hoje (cabendo destacar que foi nos períodos das grandes guerras históricas que essa racionalidade deu saltos de aperfeiçoamento notáveis), então as consequências dessas práticas, que colocam uma racionalidade como dominante e aparentemente absoluta, ou seja, que se definem por terem em si tudo o que possa ser denominado de racional, podem, é possível dizer, eliminar a assimilação, compreensões, usos e potência de outras racionalidades (SANTOS, 2002).

Mas a tecnologia que fornece fontes de poder pode fornecer, ao mesmo tempo, fontes de análise e de ação política (HARAWAY, 2000). Os diferentes interessados podem negociar com as formas específicas de poder, autoridade e representação que estão associadas às tecnologias (ESCOBAR et al., 1994), que são produzidas com objetivos e prioridades situadas em contextos específicos, mas também moldadas pelas formas como são comercializadas, utilizadas, ensinadas e socializadas (HINE, 2000). Dessa maneira, as subversões dos usos 
das tecnologias oferecem indicativos de que as coisas podem ser diferentes. Nesse contexto, um caso específico de protagonismo online de estudantes de administração serve para nossa reflexão, o Guia ADM (GUIA ADM, 2014).

Descobriu-se o Guia ADM enquanto se explorava a possibilidade de uma etnografia do virtual (HINE, 2000) entre produtores online de conteúdo sobre administração. $O$ contexto era o de uma jovem mulher da região Norte do Brasil, recém-formada em administração, direcionando uma rede online de estudantes de administração, em uma perspectiva estruturada e com um roteiro claro de ação, no desenvolvimento coletivo de seus aprendizados.

Mas bastou assistir a alguns dos hangouts, ler sobre a história do Guia ADM, observar suas narrativas online, para, então, perceber que, como naquela música do O Rappa, o novo já nasce velho. Formados, educados, formatados apenas para um repetir intenso das narrativas corporativas, naturalizando as atividades empresariais, propagando uma (de)formação em administração, assim estavam mantendo-se aqueles jovens online.

A proposta de participação desenvolvida pelo Guia do ADM parecia boa, potencialmente falando, mas se mantinha atrelada à lógica do management e à filosofia dos "superadministradores", buscando se estabelecer como um modelo de negócio. Porém (e neste ponto se considera o que agora afirmaremos como a contribuição mais relevante neste ensaio para quem queira pensar em possibilidades de utilizar a Internet para trabalhar questões como as aqui discutidas) o desenvolvimento, conjunto de aprendizado e construção alternativa à tecnologia de gestão moderna, apoiado nas possibilidades de relacionamento e informação com a Web, precisa que as iniciativas se produzam não como um modelo de negócio, mas, sim, como uma prática política, ou seja, preocupados com a comunidade, priorizando interesses coletivos nos problemas cotidianos. E essa visão, ou intencionalidade, com o uso da Internet, possui particularidades distintas da lógica das mídias sociais, podendo estar mais próxima do que se veio a chamar em certo momento de mídias táticas.

A noção de mídias sociais está atrelada à visão dos espaços de coprodução de informação e a conversas na Web enquanto extensões do management apoiadas nos modelos participativos. A lógica é corporativa, de extensão das práticas corporativas inovada no formato de exploração do trabalho dos usuários online, trabatho imaterial (HARDT; NEGRI, 2001). As iniciativas User Generated Content se espalharam em diferentes espaços pela Internet e viraram negócios, tomando forte impulso na primeira década dos anos 2000, quando a ideia de mídias sociais alcançou o auge de sua visibilidade para o mundo corporativo, e grandes empresas começaram a investir nessa "nova" forma de relação com os consumidores, além, é claro de uma gama de operações de criação de valor nas plataformas online com as operações sendo realizadas pelos próprios usuários. Para entender como essa efervescência era propagada e estimulada naquele período, uma boa leitura é a do Conectado (SPYER, 2007).

Já no caso da mídia tática, a ação é política. Mídia tática é uma expressão tecnopolítica (HECHT, 2001; PARRA, 2012) que partiu da Europa no começo dos anos de 1990 com o uso de câmeras de vídeo baratas por grupos de ativistas e teóricos em Amsterdã, estendendo-se, posteriormente, para os EUA e outras partes do mundo, utilizando hardware de segunda mão e software livre em suas atuações táticas, que consistiam na ampliação da liberdade de expressão dos menos favorecidos e minorias (raciais, sexuais, etc.), comunidades de bairro, dissidentes políticos, artistas de rua e outros que eram normalmente excluídos do circuito das mídias tradicionais, baseando-se em uma lógica do faça você mesmo (DIY, do it yourself) e operando de forma independente e oposta a grupos econômicos transnacionais (CAETANO, 2006).

Os usos da Internet pensados como mídia tática são parte da ideia de haking. E nesse caso, corra do que se fala sobre hackers na mídia e em outros espaços não esclarecidos. 
Hackers mesmo, diferente de todo imaginário "tecnopop" que circula por aí, são um fenômeno de antagonismo. Uma versão mais interessante para compreender os hackers é aquela que os coloca como opositores a certo capitalismo chamado de vetorialista, devido às suas formas de enriquecimento e acumulação com base no transporte em velocidade de informação, assim como os vetores na epidemiologia. Os vetorialistas são os sucessores do capitalista industrial, "seu poder reside no monopólio da propriedade intelectual [...] e nos meios de reprodução deste valor - os vetores de comunicação." (WARK, 2004, p. 25).

\section{5 À GUISA DE CONCLUSÃO}

Busca-se, com este ensaio, em uma perspectiva de caracterização da tecnologia de gestão moderna, mostrar que é necessário pensar formas de emancipação e protagonismo na formação em administração, em face do Holocausto, apresentado em sua associação com a tecnologia de gestão. A administração não como está, é claro, pode ser fundamental para a vida em comunidade. Uma administração com outro perfil, um perfil de atuação política. Um perfil de partilhar de códigos e ideais comuns, de busca de compreensões e soluções próprias, consciente dos efeitos colaterais do management e em busca de alternativas.

As tecnologias de gestão, nesta visão, precisam se voltar urgentemente para certas realidades: quem pega ônibus lotado para ir ao trabalho, quem circula de bicicleta como meio de transporte nas cidades, quem espera o barco que passa uma vez por semana na ilha para poder ter atendimento médico, quem cata lixo para fazer renda. Pensar que a solução do $m a-$ nagement, do formato de tecnologia de gestão moderno, resolve tudo é um grande problema. Não perscrutar as tecnologias de gestão e procurar por alternativas é uma grave omissão.

O hacking, como inspiração para ação coletiva, tem a força de um imaginário de possibilidades. Facebook, YouTube, Twitter, Instagram, Whatsapp e o que vier de tecnologias de relacionamento online posteriormente são também construções nas quais a tecnologia de gestão pode ser "hackeada", mas isso começa com uma compreensão abrangente, fundamentada e sóbria dos interesses e das possibilidades, com desenvolvimento de trabalhos com tecnologias de gestão associadas com tecnologias digitais, aplicativos, lógica de plataforma, Internet e ponderação entre as visões de modelo de negócio e de prática política, direcionando um olhar para a discussão dos objetivos dos cursos de administração, principalmente aqueles fora do campo de públicas, como parte da discussão mais abrangente sobre práticas empresariais e limitações da orientação da formação para o "mercado".

\section{MANAGEMENT TECHNOLOGY AND THE HOLOCAUST: IS IT POSSIBLE TO HACK THIS?}

\section{ABSTRACT}

In this essay we discuss Bauman's view of the Holocaust as the dominant logic of anagement technologies disseminated in the Management graduation courses in Brazil. It is shown that, besides this rationality, there is the imaginary concept that biases the general perception and limits the emancipatory possibilities of the students. We have figured out what the Holocaust can represent in terms of management technology and as an epistemological orientation to be assimilated as a point of departure in investigating this matter by bringing in an example of student's prominence on internet, we place a distinction between social media and tactical media, in order to possibly discuss hackings on this reality. We conclude by emphasizing the possibility of the study/acting of/with online technologies based on the distinction between business model and political practice.

Keywords: Management knowledge. Organizational technology. Hacking. 


\section{LA TECNOLOGÍA DE GESTIÓN Y EL HOLOCAUSTO: ¿ES POSIBLE "HACKEAR" ESO?}

\section{RESUMEN}

En este ensayo, discutimos la condición presentada por Bauman a través de las lentes del Holocausto, del que aún se presenta como lógica dominante de las tecnologías de gestión diseminadas en la formación en Administración en Brasil. Expone que, además de las graduaciones delineadas por una racionalidad cuestionable, existe un imaginario que condiciona la percepción general y afecta las posibilidades emancipadoras de los estudiantes. Se contextualiza, de esta manera, lo que el Holocausto puede representar en termos de tecnología de gestión; se aborda una orientación epistemológica a ser asimilada como punto de partida en los desarrollos en torno de racionalidades alternativas y, como un ejemplo de protagonismo de estudiantes de Administración en la Internet, hay una distinción entre el medio social y el medio táctico, de manera a hablar sobre posibles $h a-$ ckings en este campo. Concluimos destacando la posibilidad del estudio o actuación de las tecnologías online a partir de la distinción entre los modelos de negocio y práctica política.

Palabras-clave: Formación de administradores. Tecnología de gestión. Management. Hacking.

1 Utilizamos o termo management, assim como outros em estudos organizacionais, para demarcar uma espécie de administração conformada por sua raiz e andamentos estanunidenses, que se estabelece como a visão dominante da tecnologia de gestão moderna.

2 Prática advinda das noções gregas de khréma e atos, busca incessante da produção e do açambarcamento das riquezas (AKTOUF, 2004).

$3 \mathrm{O}$ experimento submetia o sujeito da pesquisa à tomada de decisão sobre dar ou não um choque elétrico numa pessoa à medida que essa errava respostas de um teste de aprendizado. De fato, não havia alguém por trás da cabine levando choques, mas isso o aplicador de choque não sabia, e progressivamente, a cada erro no suposto teste, era solicitado ao aplicador de choque que utilizasse uma carga ligeiramente superior à carga anterior. Se no começo os supostos choques eram de uma intensidade nitidamente inofensiva, em certo momento avançado do experimento ficava claro que o choque já havia chegado a uma intensidade que feria gravemente o suposto respondente. Porém, os resultados do experimento mostram que a maioria, mais de 60 por cento dos investigados, prosseguiu com os choques, chegando a voltagens consideraras torturantes e até fatais, apenas em atendimento à autoridade do pesquisador (TERRA, 2011).

\section{REFERÊNCIAS}

AKTOUF, O. Pós-globalização, administração e racionalidade econômica: a síndrome do avestruz. São Paulo: Atlas, 2004.

BAUMAN, Z. Modernidade e holocausto. Rio de Janeiro: Jorge Zahar, 1998.

BIJKER, W. E. Social construction of technology. In: OLSEN, J. K. B.; PEDERSEN, S. A.; HENDRICKS, V. F. (Org.). A companion to the philosophy of technology. Chichester: Wiley-Blackwel, 2009. p. 88-94.

BOLTANSKI, L.; CHIAPELLO, È. C. O novo espírito do capitalismo. São Paulo: Martins Fontes, 2009.

CAETANO, M. A. Tecnologias de resistência: transgressão e solidariedade nos media tácticos. Lisboa: Instituto Superior de Ciências do Trabalho e da Empresa, 2006.

CALLON, M. Some elements of a sociology of translation: domestication of the scallops and the fishermen of St Brieuc Bay. The Sociological Review, v. 32, n. S1, p. 196-233, 1984.

CASTELLS, M. A Galáxia Internet: reflexões sobre a Internet, negócios e a sociedade. Rio de Janeiro: Zahar, 2003.

COOPER, S. Technoculture and critical theory: in the service of the machine. New York: Routledge, 2002.

CORRÊA, L. H. Teoria geral da administração: abordagem histórica da gestão de produ- 
ção e operações. São Paulo: Atlas, 2003.

DEMO, P. Pesquisa: princípio científico e educativo. São Paulo: Cortez, 1991.

DINIZ, A. DA S. A maldição do trabalho. João Pessoa: Manufatura, 2004.

ESCOBAR, A. et al. Wenner-Gren Foundation for Anthropological Research Welcome to Cyberia : Notes on the Anthropology of Cyberculture [ and Comments and Reply ]. Current Anthopology, v. 35, n. 3, p. 211-231, 1994.

FARIA, J. H. de; MENEGHETTI, F. K. Burocracia como organização, poder e controle. Revista de Administração de Empresas, v. 51, n. 5, p. 424-439, 2011. Disponível em: $<$ http://www.scielo.br/scielo.php?script=sci arttext\&pid=S0034-75902011000500002\&lng= pt\&nrm=iso\&tlng=en>. Acesso em: 9 jul. 2015.

GUIA ADM. Guia Adm - YouTube. son., color. 2014. Disponível em: <https://www. youtube.com/channel/UCnT 5 KyP 7xDyLQQvsz3fC5g>. Acesso em: 9 jul. 2015.

HARAWAY, D. Manifesto ciborgue: ciência, tecnologia e feminismo-socialista no final do século XX. In: SILVA, T, T. (Org.). Antropologia do ciborgue. Belo Horizonte: Autêntica, 2000 .

HARDT, M.; NEGRI, A. Império. São Paulo: Record, 2001.

HECHT, G. Technology, politics, and national identity in France. In: ALLEN, M.; HECHT, G. (Org.). Technologies of power: essays in honor of thomas parke hughes and agatha chipley hughes. Cambridge: The MIT Press, 2001. p. 255-293.

HEIDEGGER, M. A questão da técnica. Scientiae Studia, v. 5, n. 3, p. 375-398, set. 2007. Disponível em: <http://www.scielo.br/ scielo.php?script $=$ sci_arttext\&pid $=$ S1678-
$31662007000300006 \& \operatorname{lng}=$ pt\&nrm=iso\&tlng $=\mathrm{pt}>$. Acesso em: 29 jun. 2017.

HINE, C. Virtual Ethnography. London: Sage, 2000.

LATOUR, B. A esperança de Pandora: ensaios sobre a realidade dos estudos científicos. Bauru: EDUSC, 2001.

LATOUR, B. Ciência em ação: como seguir cientistas e engenheiros sociedade afora. São Paulo: UNESP, 2000.

MASCARENHAS, A. O.; ZAMBALDI, F.; MORAES, E. A. DE. Rigor, relevância e desafios da academia em administração: tensões entre pesquisa e formação profissional. Revista de Administração de Empresas, v. 51, n. 3, p. 265-279, 2011. Disponível em: $<$ http://www. scielo.br/pdf/rae/v51n3/v51n3a07.pdf $>$. Acesso em: 10 jul. 2017.

MOL, A. The body multiple: Ontology in medical practice. Durham, NC: Duke University Press, 2002.

MOTTA, F. C. P. Teoria das organizações: evolução e crítica. 2. ed. São Paulo: Thomsom, 2001.

MOTTA, F. C. P.; BRESSER-PEREIRA, L. C. Introdução à organização burocrática. 2. ed. São Paulo: Thomsom, 2004.

NICOLINI, A. Qual será o futuro das fábricas de administradores? Revista de Administração de Empresas, v. 43, n. 2, p. 44-54, 2003. Disponível em: <http://www.scielo.br/scielo.php?pi$\mathrm{d}=\mathrm{S} 0034-75902003000200003 \&$ script $=\mathrm{sci}$ arttext>. Acesso em: 8 jul. 2017.

PAULA, A. P. P. Para além dos paradigmas nos estudos organizacionais: o círculo das matrizes epistêmicas. Cad. EBAPE.BR, v. 14, n. 2, p. 24-46, 2016. 
PARRA, H. Controle social e prática hacker: tecnopolítica e ciberpolítica em redes digitais. Sociedade e Cultura, v. 15, n. 1, p. 109-120, 17 out. 2012. Disponível em: $<$ http://www.revistas.ufg.br/index.php/fchf/article/view/20677>. Acesso em: 9 jul. 2017.

PEREIRA, W. A comunicação e a cultura no cotidiano. Revista FAMECOS, n. 32, p. 6670, 2007. Disponível em: $<$ http://www.redalyc. org/pdf/4955/495550188010.pdf>. Acesso em: 10 jul. 2015 .

PINCH, T. F.; BIJKER, W. E. The social construction of facts and artifacts: or how the sociology of science and sociology of technology might benefit each other. In: BIJKER, W.; HUGHES, T. P.; PINCH, T. (Org.). The social construction of technological systems: new directions in the sociology and history of technology. Masachusets: The MIT Press, 1987. p. $17-50$.

RAMOS, A. G. A nova ciência das organizações: uma reconceituação da riqueza das nações. 2. ed. Rio de Janeiro: Editora da Fundação Getúlio Vargas, 1989.

REED, M. Teorização organizacional: um campo historicamente contestado. In: CLEGG, S. R.; HARDY, C.; NORD, W. (Org.). Handbook de estudos organizacionais: modelos de análise e novas questões em estudos organizacionais. São Paulo: Atlas, 1998. v. 1. p. 61-98.

RIBEIRO, D. A.; SACRAMENTO, A. R. S. Ensino e currículo em administração: a opção brasileira. [S.1.]: UNIFACS, Universidade Salvador, 2010. v. 10. Disponível em: $<$ http:// revistas.unifacs.br/index.php/rgb/article/ view/751>. Acesso em: 9 jul. 2016.

ROCHA, M. D. S.; COSTA, L. Simulação e simulacro: realidade do Big Brother Brasil.

Cadernos de Comunicação, v. 16, n. 1, 10 jul. 2012. Disponível em: <http://cascavel.ufsm.br/ revistas/ojs-2.2.2/index.php/ccomunicacao/ar- ticle/view/5832>. Acesso em: 10 jul. 2017.

SANTOS, B. DE S. Para uma sociologia das ausências e uma sociologia das emergências. Revista Crítica de Ciências Sociais, n. 63, p. 237-280, 1 out. 2002. Disponível em: <http:// rccs.revues.org/1285>. Acesso em: 8 jul. 2017.

SHENHAV, Y. The historical and epistemological foundations of organization theory. In: TSOUKAS, H.; KNUDSEN, C. (Org.). The Oxford handbook of organization theory: meta-theoretical perspectives. Oxford, UK: Oxford University Press, 2003. p. 183-209.

SILVA, F. L. E. Martin Heidegger e a técnica. Scientiae Studia, v. 5, n. 3, p. 369-374, set. 2007. Disponível em: <http://www.scielo.br/ scielo.php?script $=$ sci_arttext\&pid $=\mathrm{S} 1678$ 31662007000300005\&lng=pt\&nrm=iso\&tlng $=\mathrm{pt}>$. Acesso em: 7 jul. 2013.

SPYER, J. Conectado: o que a internet fez com você e o que você pode fazer com ela. Rio de Janeiro: Jorge Zahar, 2007.

TRAGTEMBERG, M. Burocracia e ideologia. 2. ed. São Paulo: UNESP, 2006.

TRIGUEIRO, M. G. S. A prática tecnológica. Teoria e Pesquisa, v. 17, n. 1, p. 85-96, 2008. Disponível em: $<$ http://www.teoriaepesquisa. ufscar.br/index.php/tp/article/viewFile/ 137/102>. Acesso em: 30 jun. 2017.

USHMM. Enciclopédia do Holocausto. O Holocausto. Disponível em: $<$ https://www. ushmm.org/wlc/ptbr/article.php?ModuleId=10007867>. Acesso em: 9 jul. 2016.

WARK, M. A Hacker Manifesto. Cambridge: Harvard Universty Press, 2004.

WOOD JUNIOR, T.; PAULA, A. P. P. DE. Pop-management: contos de paixão, lucro e poder. Organizações \& Sociedade, v. 9, n. 24, p. 39-51, ago. 2002. Disponível em: $<$ http://www.scielo.br/scielo.php?script $=$ sci arttext\&pid=S1984-92302002000200003\&lng $=\mathrm{pt} \& \mathrm{t} \operatorname{lng}=\mathrm{pt}>$. Acesso em: 10 jul. 2017. 